\title{
¿Cuándo se considera que hay quiebra en las empresas?
}

\author{
When is Business Bankruptcy Considered?
}

\begin{abstract}
Melisa Alvarado-de la Sancha ${ }^{a}$, Beatriz Sauza-Avila ${ }^{b}$, Dorie Cruz-Ramírez $^{c}$, Suly Sendy Pérez-Castañeda ${ }^{d}$ Abstract:

Currently, with the unforeseen events that occur worldwide such as the Covid-19 pandemic, they have economically affected companies by limiting their production, seriously affecting the markets and have influenced the drop in the price of oil, therefore they must apply financial tools that allow us to know in a timely manner when a company is in danger of bankruptcy.
\end{abstract}

Keywords:

Knowledge management, education, innovation, competence

\section{Resumen:}

Actualmente con los imprevistos que se presentan a nivel mundial como es el caso de la pandemia del Covid-19, han afectado económicamente a las empresas limitando su producción, afectando seriamente los mercados y ha influido en la baja del precio del petróleo, por ello se deben aplicar herramientas financieras que permitan conocer en tiempo y en forma cuando una empresa se encuentre en peligro de quiebra.

\section{Palabras Clave:}

Gestión del conocimiento, educación, innovación, competencia

\section{Introducción}

El presente mapa conceptual tiene como objetivo principal ejemplificar la forma en que las empresas pueden realizar el cálculo del factor $Z$ para con ello conocer si una empresa pude estar en riesgo de quiebra y una de las ventajas es prevenir a través de realizar estrategias que le ayuden a seguir manteniéndose viva.

\footnotetext{
a Autor de Correspondencia, Universidad Autónoma del Estado de Hidalgo, Escuela Superior de Ciudad Sahagún, https://orcid.org/00000002-8916-5391, Email: al338817@uaeh.edu.mx

b Universidad Autónoma del Estado de Hidalgo, Escuela Superior de Ciudad Sahagún, https://orcid.org/0000-0002-7919-6792, Email: beatriz_sauza@uaeh.edu.mx

${ }^{c}$ Universidad Autónoma del Estado de Hidalgo, Escuela Superior de Ciudad Sahagún, https://orcid.org/0000-0002-7853-7655, Email: doriec@uaeh.edu.mx

d Universidad Autónoma del Estado de Hidalgo, Escuela Superior de Ciudad Sahagún, Email: sulysp@uaeh.edu.mx
} 


\section{Descripción}

Toda empresa está expuesta a los cambios económicos que se presenten tanto a nivel nacional o internacional, es por ello que en el presente mapa se ilustra el modelo razón Z, de Altman el cual fue desarrollado en la década de los 60 que recopilo información de 66 empresas, aplicando este modelo a empresas que cotizan en bolsa y empresas manufactureras y no manufactureras que no cotizan en bolsa, al aplicar la razón Z, se pueden tener tres posibilidades las cuales son: entidad sana, que se tenga una empresa con alta posibilidad de insolvencia o quiebra, que se tenga una compañía que se encuentre en zona gris y que su futuro sea incierto. Comparándose con el Modelo Springate el cual a diferencia de Altman no existe zona gris, solo existen dos opciones el resultado puede ser bueno o malo. Sin embargo, ambos modelos de acuerdo con Astorgan citado por Miranda (2015), son los que han presentado mayor precisión en los resultados en un $95 \%$. Para determinar si las empresas corren el riesgo de caer en quiebra.

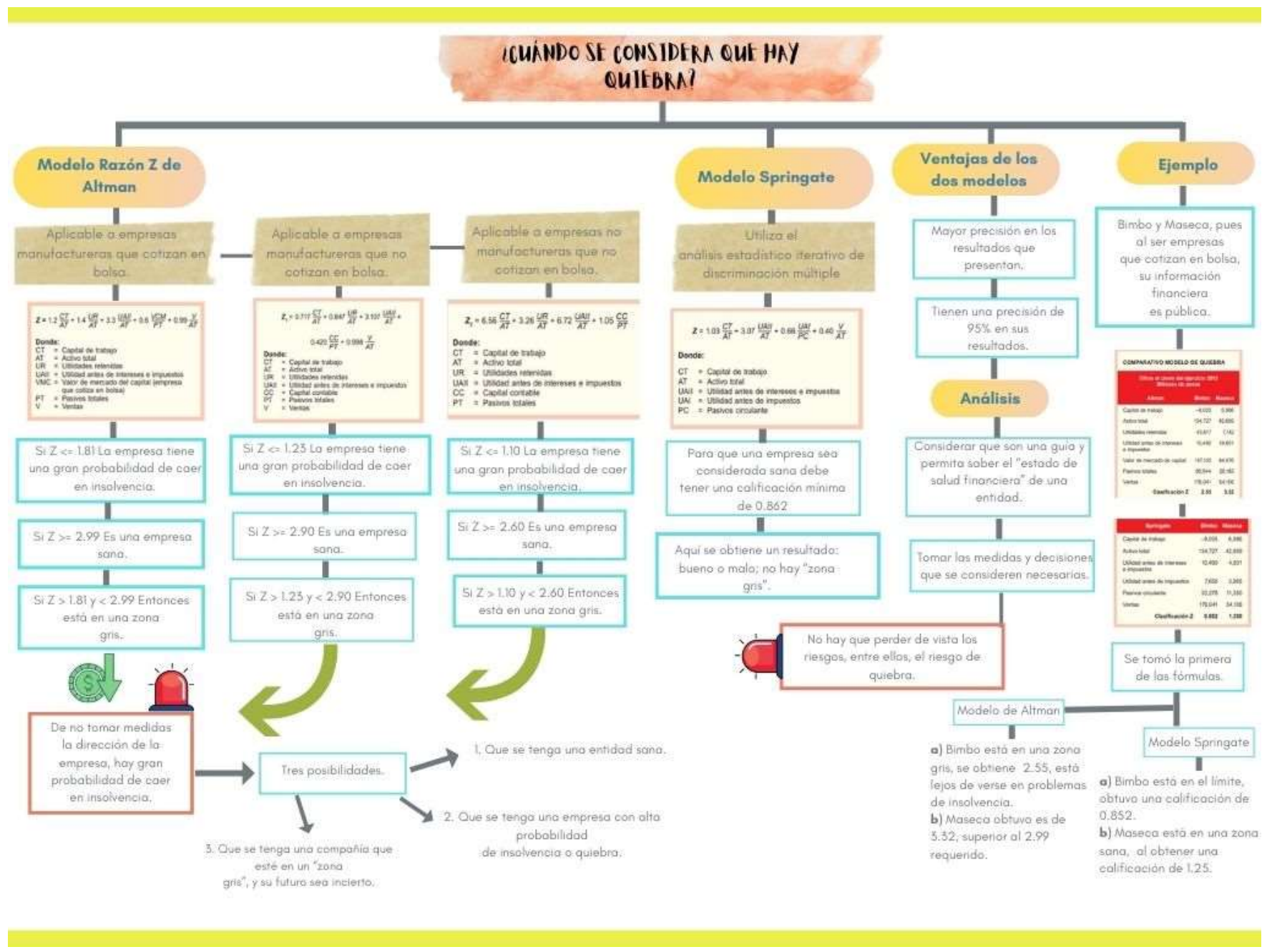

Figura 1. ¿Cuándo se considera que hay quiebra en las empresas

\section{Referencias}

[1] Miranda, S. J. (2015). ¿Cómo saber si la empresa esta en riesgo de quiebra o insolvencia? Revista PAF, no. 66

[2] Pont, E. (2020). ¿Cómo afecta el coronavirus a la economía?. Recuperado de https://www.lavanguardia.com/vida/juniorreport/20200316/474199840484/coronavirus-economia-mundial.html anual de fórmulas financieras una herramienta para el mundo actual. 